\title{
Revisited Anatomy of Additional Heads of Biceps Brachii Muscle and Coexisting Musculocutaneous Nerve Variants
}

\author{
Suman Verma', Sulochana Sakthivel ${ }^{2}$ \\ ${ }^{1,2}$ Associate Professors, Department of Anatomy, Jawaharlal Institute of Postgraduate Medical Education and Research, Pondicherry, India.
}

\section{Abstract}

Introduction: To determine the incidence and gross morphology of additional head of biceps brachii in the Indian population, and to note concurrent musculocutaneous nerve variations. Subjects and Methods: One hundred and twenty upper limbs (males- 100, females- 20) from 60 formalin-embalmed cadavers were utilized for the study. Results: The additional heads were found in 11 cadavers. Third head was present in $16.6 \%$ and fourth head in $1.7 \%$. The variation was unilateral in $72.7 \%$ and bilateral in $27.3 \%$ cadavers. Out of 120 limbs, 14 had additional head, and $71.4 \%$ of these were left-sided. In $73.3 \%$, additional head joined with tendon and with the belly of BB in $26.7 \%$. Three types of origin: anterolateral, posteromedial and high humeral were observed in $60 \%, 26.7 \%$ and $13.3 \%$, respectively. The additional muscle was $11.7 \pm 3.9 \mathrm{~cm}$ in length. The mean length on the right and left sides was $9.8 \pm 3.3 \mathrm{~cm}$ and $12.4 \pm 3.9 \mathrm{~cm}$, respectively. Incidence of concurrent additional head and musculocutaneous variations was $42.8 \%$. The nerve variations were unilateral with $80 \%$ on the left, and ipsilateral to additional muscle. Conclusion: The incidence of additional head in biceps brachii is $18.3 \%$ in the Indian population. Most common presentation is of a left-sided third head, and musculocutaneous variants occur on the same side as additional muscle. Presence of extra head should be considered during the analysis of the diagnostic scans, and awareness of the associated musculocutaneous nerve variations would be helpful in avoiding complications during surgical interventions.

Keywords: Morphology, Musculocutaneous nerve, Upper extremity, Biceps brachii, Musculoskeletal Abnormalities.

Corresponding Author: Dr. Sulochana Sakthivel, Associate Professor, Department of Anatomy, Jawaharlal Institute of Postgraduate Medical Education and Research, Pondicherry, India.

Received: December 2019

Accepted: December 2019

\section{Introduction}

Biceps brachii (BB) is a muscle of the front of arm. The long and short heads of BB arise from the supraglenoid tubercle and the coracoid process, respectively. Two heads form a tendon near the elbow for insertion into the radial tuberosity. ${ }^{[1]}$ When another muscle mass joins it before insertion, it is termed as an extra, supernumerary, additional or accessory head of $\mathrm{BB} .{ }^{[1-6]}$ The third head in $\mathrm{BB}$ is encountered more often than the fourth or higher number of heads, however its incidence is variable. The accessory muscle usually attaches to the medial side of humerus near coracobrachialis (CB) or brachialis, and distally fuses with the inner aspect of biceps brachii tendon. ${ }^{[1-3]}$ It is seen as a thick muscle in most of the cases and may present as a soft tissue mass in the arm especially if bulky. ${ }^{[7]}$ Moreover, an extra head is likely to simulate a muscle tear in the diagnostic image of the upper limb. ${ }^{[5]}$

Variable incidence of the additional head of biceps muscle (AHB) is described in the literature from the multiple ethnic populations such as, $8 \%$ in Chinese, $10 \%$ in white Europeans, $12 \%$ in black Africans, and $18 \%$ in Japanese. ${ }^{[3]}$ In comparison, the prevalence is reported to be low in the Indian population. ${ }^{[4,8-10]}$

$\mathrm{BB}$ acts as a flexor at the elbow, and its principal action is supination. ${ }^{[1]}$ The presence of an additional head adds to the muscle mass. This is likely to affect the biomechanics of $\mathrm{BB},{ }^{[11]}$ and has the potential to create imbalance at the elbow due to extra muscle bulk in the flexor aspect of the brachium.

Musculocutaneous nerve (MCN) is one of the branches of the lateral cord of brachial plexus. It supplies $\mathrm{BB}$ and the other muscles of the anterior compartment of arm, before giving the lateral cutaneous nerve of forearm. After passing through $\mathrm{CB}, \mathrm{MCN}$ runs beneath $\mathrm{BB}$ in the arm. $\mathrm{A}$ communicating branch $(\mathrm{COB})$ is seen if few median nerve $(\mathrm{MN})$ fibers enter $\mathrm{MCN}$ and later leave it to join $\mathrm{MN}$, though rarely fibers travel in the reverse direction. ${ }^{[1]}$ The incidence of absent $\mathrm{MCN}$ is $3.6 \%$, and that of the nerve connections between $\mathrm{MCN}$ and $\mathrm{MN}$ is 53.6\%. ${ }^{[12]}$ Venieratos and Anagnostopoulou observed such COB in $13.9 \%$. $^{[13]}$

It has been suggested that AHB influences the course of MCN leading to the nerve variants, and can impinge on it especially if the nerve is running in close relation to it. ${ }^{[8,14]}$ In studies on the AHB, variations in $\mathrm{MCN}$, like the absence of $\mathrm{MCN}$, duplication of $\mathrm{MCN}$, altered course of $\mathrm{MCN}$, or communicating branches between $\mathrm{MN}$ and MCN have been reported. ${ }^{[4,7,15,16]}$ Communicating branches concurrent with AHB are seen in $9.3 \%, 23.8 \%$ and $54.7 \%$ according to Techataweewan et al., Ballesteros et al. and Kosugi et al., 
respectively. ${ }^{[4,7,16]}$ However, there is scarcity of literature on the incidence of $\mathrm{MCN}$ variations associated with $\mathrm{AHB}$ in the Indian population. Also, the existing knowledge on the morphology of AHB in Indians is limited. This study proposed to find out the incidence of AHB in the Indian population, and describe its morphology, and the simultaneous presence of MCN variants.

\section{Subjects and Methods}

Sixty adult formalin-embalmed cadavers (50 male, 10 female), with an average age of 61 years (range 52-70), available in the department of Anatomy from 2014-2019 were selected for this study. The upper limbs with any apparent deformity, damage, or signs of surgery were excluded. The cadavers were obtained through institutional body donation program following ethical guidelines and all the specimens were stored in $10 \%$ formalin solution after embalming.

For dissection, a vertical incision was placed in the skin of the front of the arm and the elbow. The line of incision extended from the acromion process to the radial tuberosity, and was joined by horizontal incisions at the two ends. After reflecting the skin flaps, the muscles of the anterior compartment of arm were exposed by the blunt dissection and subsequently examined for the presence of AHB. The number, laterality, attachments, shape, length, and nerve supply of the extra heads were recorded. The length of AHB from origin to its fusion with BB was measured using a Vernier Caliper with a sensitivity of $0.01 \mathrm{~mm}$, and the mean of three readings was taken as final. In the limbs with an additional head, any MCN variation if present, was noted. Two independent observers, both anatomists, recorded the findings.

\section{Results}

Out of 60 cadavers examined, AHB was seen in 11 (18.3\%), 10 male and one female. The accessory muscle was bilateral in three $(27.3 \%)$ and unilateral in eight $(72.7 \%)$. The fourheaded muscle was present on the left arm in one male cadaver $(1.7 \%)$ and rest of the cases had an extra third head $(16.6 \%)$. The female cadaver had a unilateral left-sided third head.

In 120 upper limbs (males- 100, females- 20), BB with two heads was observed in 106 limbs $(88.3 \%)$, three heads in 13 $(10.8 \%)$ and four heads in one $(0.8 \%)$. The distribution of number of heads in BB is shown in Table 1. The incidence of $\mathrm{AHB}$ was $13 \%$ in the males and $5 \%$ in the females. Among the 14 limbs, AHB was left-sided in 10 (71.4\%) and right-sided in four (28.6\%).

AHB was positioned deep to the main belly of biceps brachii. It joined with the tendon of $\mathrm{BB}$ in $73.3 \%$ and with the belly in four $26.7 \%$. The extra head joining the tendon, fused with it on the inferomedial aspect and formed most of the bicipital aponeurosis. AHB fused with BB in the lower part of arm near the elbow in $86.7 \%$ and in the middle of the arm in $13.3 \%$.

All the additional heads were humeral in origin. The origin was fleshy and vertically positioned in $93.3 \%$, and tendinous and transversely placed in $6.7 \%$ [Figure 1B]. The most common site of origin was on the medial side of the shaft of humerus close to $\mathrm{CB}$. The humeral origin was classified on the basis of its location: O1- anterolateral (between CB insertion and brachialis), $\mathrm{O} 2$ - posteromedial (medial to $\mathrm{CB}$ insertion), and $\mathrm{O} 3$ - high humeral. The types $\mathrm{O} 1, \mathrm{O} 2$ and $\mathrm{O} 3$ were observed in $60 \%, 26.7 \%$ and $13.3 \%$ respectively. The type $\mathrm{O} 2$ in one muscle extended to the medial intermuscular septum and fascia over brachialis, and covered the median nerve and brachial artery in the lower half of the arm [Figure 1C]. Type $\mathrm{O} 3$ was either on the anterior aspect of humerus shaft just above brachialis attachment, or on the medial aspect of shaft below teres major insertion. All the type $\mathrm{O} 2$ cases were right-sided, whereas, type O3 were left-sided. Type $\mathrm{O} 1$ was left-sided in $88.9 \%$.

On the basis of morphology, three types of AHB were encountered: I- long, thin and narrow [Figure 1B]; II- long, thick and broad; III- short, thick and broad [Figure 1A]. Type I appeared in six (40\%), type II in seven (46.7\%), and type III in two (13.3\%) limbs. All type I cases and $57.1 \%$ of type II were left-sided, and type III was equally distributed on both the sides. The length of AHB varied from 4.7 to $18.1 \mathrm{~cm}$, the average being $11.6 \pm 4.0 \mathrm{~cm}$. The mean length on the right and left sides was $9.8 \pm 3.3 \mathrm{~cm}$ and $12.4 \pm 3.9$ $\mathrm{cm}$, respectively. In males, mean length on the right side was $9.8 \pm 3.3 \mathrm{~cm}$ and that on the left was $12.3 \pm 4.2 \mathrm{~cm}$. The length of $\mathrm{AHB}$ in specimen from the female cadaver was $13.6 \mathrm{~cm}$.

MCN supplied the AHB in all cases except one where MCN was absent, and a branch from the lateral cord supplied it [Figure 2F]. An added innervation to AHB from MN was observed in three $(21.4 \%)$. In the presence of $\mathrm{AHB}, \mathrm{MCN}$ was posterior to it in $92.3 \%$, and anterior to it in $7.7 \%$.

Incidence of concurrent $\mathrm{AHB}$ and $\mathrm{MCN}$ variations was $42.8 \%$ [Table 2]. Two types of variations were seen: absence of MCN, and COBs between MCN and MN [Fig 2]. COBs were directed from $\mathrm{MCN}$ to $\mathrm{MN}$ in $80 \%$, and in opposite direction in others. All the nerve variants were unilateral and were on the same side as AHB. Four out of six (80\%) were located on the left side. The COBs were given off in proximal third of arm either before entry of MCN into $\mathrm{CB}$ [Figure 2E] or during its passage through $\mathrm{CB}$ [Figure 2A]. The distal COBs were more common $(66.7 \%)$, and their position was between $\mathrm{AHB}$ and $\mathrm{BB}$ [Figure 2B], between $\mathrm{AHB}$ and brachialis [Figure 2C], and medial to AHB [Figure 2D and 2E].

\begin{tabular}{|c|c|c|c|c|}
\hline \multirow{2}{*}{$\begin{array}{l}\text { Number of } \\
\text { heads in } \\
\text { biceps } \\
\text { brachii }\end{array}$} & \multicolumn{2}{|l|}{ Male } & \multicolumn{2}{|l|}{ Female } \\
\hline & $\begin{array}{l}\text { Right } \\
\mathbf{N}=\mathbf{5 0} \\
(\%)\end{array}$ & $\begin{array}{l}\text { Left } \\
\mathrm{N}=\mathbf{5 0} \\
(\%)\end{array}$ & $\begin{array}{l}\text { Right } \\
\mathbf{N}=10 \\
(\%)\end{array}$ & $\begin{array}{l}\text { Left } \\
\mathbf{N}=10 \\
(\%)\end{array}$ \\
\hline Two heads & $46(92)$ & $41(82)$ & $10(100)$ & $9(90)$ \\
\hline Three heads & $4(8)$ & $8(16)$ & 0 & $1(10)$ \\
\hline Four heads & 0 & $1(2)$ & 0 & 0 \\
\hline
\end{tabular}

Table 2: Incidence of musculocutaneous nerve (MCN) variations associated with additional head of biceps brachii.

\begin{tabular}{|l|l|l|}
\hline & Type of MCN Variation & Incidence (\%) N=14 \\
\hline 1 & No MCN variation & $8(57.2)$ \\
\hline 2 & Absence of MCN & $1(7.1)$ \\
\hline 3 & $\begin{array}{l}\text { One communicating branch } \\
\text { between MCN and median nerve }\end{array}$ & $4(28.6)$ \\
\hline 4 & $\begin{array}{l}\text { Two communicating branches } \\
\text { between MCN and median nerve }\end{array}$ & $1(7.1)$ \\
\hline
\end{tabular}


Verma \& Sakthivel; Revisited Anatamy of Additianal Hteads of Biceps Brachit

Table 3: Incidence of additional head of biceps brachii in various populations.

\begin{tabular}{|l|l|l|l|l|l|}
\hline S.no. & Study & Year & No. of cadavers & POPULATION \\
\hline 1 & Kosugi & 1992 & 273 & INCIDENCE ( $)$ ) \\
\hline 2 & Asvat & 1993 & 85 & South Africa \\
\hline 3 & Neto & 1998 & 100 & Brazil \\
\hline 4 & Rodriguez & 2003 & 175 & Spain & 20.5 (Blacks) 8.3 (Whites) \\
\hline 5 & Nayak & 2006 & 48 & India & White-20 Black- 9 \\
\hline 6 & Rai & 2007 & 42 & India & 2.08 \\
\hline 7 & Kumar & 2008 & 48 & India & 7.1 \\
\hline 8 & Cheema & 2011 & 63 & India & 3.33 \\
\hline 9 & Ilayperuma & 2011 & 135 & Sri Lanka \\
\hline 10 & Pakhale & 2012 & 40 & India & 2.3 \\
\hline 11 & Nasr & 2013 & 50 & Saudi Arabia \\
\hline 12 & Ballesteros & 2014 & 53 & Columbia \\
\hline 13 & Da Silva & 2016 & 74 & Brazil \\
\hline 14 & Techataweewan & 2016 & 162 & Thailand \\
\hline 15 & Present study & 2019 & 60 & India \\
\hline
\end{tabular}

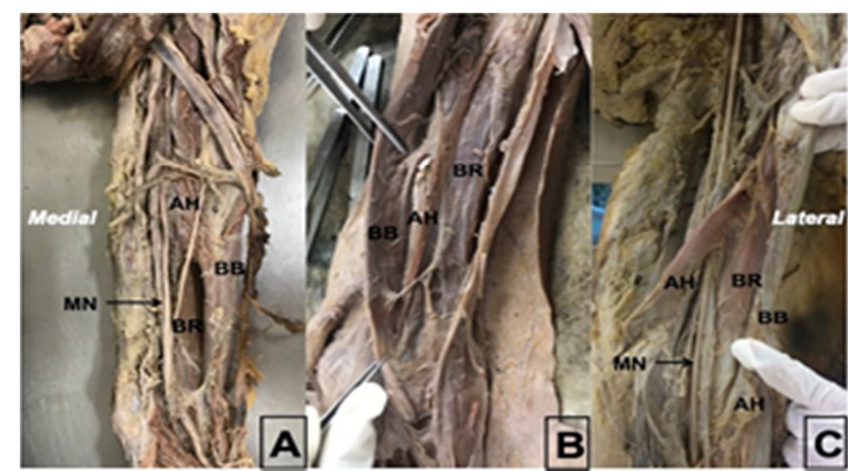

Figure 1: Morphology of additional head. A- Left upper limb with short, thick and broad AH (type III). B- Left upper limb showing long, thin and narrow AH (type I) with tendinous origin. C- Left upper limb with type II AH (MN and brachial artery passing under $\mathrm{AH})$. $\mathrm{AH}$ : additional head; $\mathrm{BB}$ : biceps brachii; BR: brachialis; MN: median nerve.

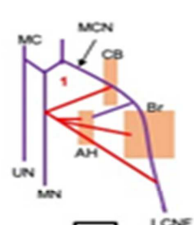

A

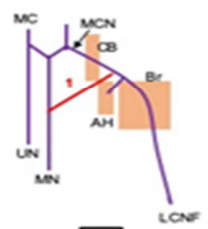

D

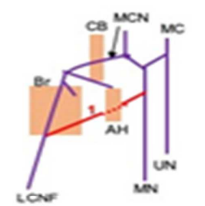

B

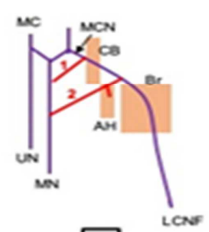

国
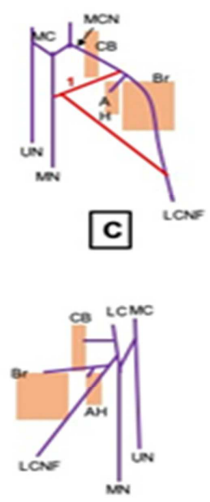

$\mathbf{F}$
Figure 2: Variations in MCN. A: (left) one communicating branch $(\mathrm{COB})$ from $\mathrm{MCN}$ to $\mathrm{MN}$. Branches to $\mathrm{AH}$ and $\mathrm{Br}$ arise where COB joined MN. B: (right) one COB passing between $\mathrm{AH}$ and Br. C: (left) one $\mathrm{COB}$ passing between $\mathrm{CB}$ and upper margin of $\mathrm{AH}$. D: (left) one $\mathrm{COB}$ passing from $\mathrm{MCN}$ to $\mathrm{MN}$ and related medial to $\mathrm{AH}$. E: (left) two COBs, first arises from MCN before it enters CB. Second COB supplied AH. F: (right) MCN absent and all the muscles are supplied by lateral cord. MCN: musculocutaneous nerve; $\mathrm{CB}$ : coracobrachialis; $\mathrm{AH}$ : additional head; Br: brachialis; MN: median nerve; LCNF: lateral cutaneous nerve of forearm; LC: lateral cord; UN: ulnar nerve; BB: branch to biceps brachii; 1, 2: communicating branches between median and musculocutaneous nerves.
Discussion

AHB was noted in $18.3 \%$ cadavers and $54.5 \%$ (six) of these had MCN variants in this study from the Indian population. The variable incidence of the AHB in the different populations is well documented (Table 3 ). The incidence is high in the Thai and Colombian than in the South Asian population from India and Sri Lanka. ${ }^{[4,17]}$ Ethnic differences are presumed to be due to the morphological adaptations in the $\mathrm{BB} .^{[7,17,18]}$ However, compared to other Indian studies, our study revealed a higher incidence of AHB.

In study by Asvat et al., extra head was more common in the black $(20.5 \%)$ compared to the whites $(8.3 \%)$, and in a study by Neto et al., extra head was seen in $20 \%$ white and $9 \%$ black, ${ }^{[11,19]}$ suggesting that the incidence of AHB may not always be related to the race.

AHB is predominantly humeral in origin, and the medial side of shaft near $\mathrm{CB}$ is the most frequent site of attachment. ${ }^{[3,4,6,9,11,16-23]}$ We found the humeral origin from area close to $\mathrm{CB}$ insertion in $86.7 \%$. The other sites of $\mathrm{AHB}$ attachment can be pectoralis major, ${ }^{[3,16,19,20,24]}$ shoulder joint capsule,$^{[3,6,16]}$ lesser tubercle, ${ }^{[20]}$ greater tubercle ${ }^{[5,16]}$ deltoid tuberosity, ${ }^{[8]}$ bicipital groove margins, and medial intermuscular septum. ${ }^{[16]}$ Accessory fibers can also come from brachialis, long and short heads of $\mathrm{BB}, \mathrm{CB}$, coracoid process ${ }^{[4,6]}$ and origin from the deltoid fascia or insertion is rare. ${ }^{[1]}$ The origin near deltoid tuberosity, $\mathrm{CB}$ and pectoralis major insertion is seen in $8 \%, 6 \%$ and $4 \%$, respectively. ${ }^{[3]}$ The surgical approach to shoulder can be affected if accessory muscle attaches close to the upper end of the humerus. ${ }^{[14]}$

The knowledge of muscle origin is relevant to interpret cases with suspected soft tissue injury to differentiate traumatic muscle split from the other causes. ${ }^{[5]}$ Rincon et al., classified the origin as superior, inferomedial, and inferolateral. ${ }^{[17]}$ The inferomedial type or origin from the medial side of humerus shaft is the most common. ${ }^{[17,25]}$ We identified anterolateral, posteromedial and high humeral origins on the basis of its relation to $\mathrm{CB}$ insertion, and anterolateral was the most common type.

The variations in insertion are believed to be due to factors affecting the muscle development. ${ }^{[6]}$ Kosugi et al. classified the insertion into four types according to the fusion of AHB to the belly, tendon, short head, and long head. ${ }^{[16]}$ The insertion to the belly was found to be the most common. 
This is similar to the study by Nasr and Hussein. ${ }^{[6]}$ However, according to Rincon et al., the muscle rarely joins the biceps belly. ${ }^{[17]}$ As per our observation, the extra head mostly fused with the tendon. This is supported by reports from several other authors. ${ }^{[4,7,10,11,17,20,26]}$

Comparable to our description, other studies have described AHB as a male dominated condition..$^{[4,9-11,17,18,20,27]}$ However, our sample had the limitation of being comprised of a much smaller number of female specimens. It is more prevalent in the female cadavers from Japan and North America, ${ }^{[16,22]}$ and Techataweewan et al. have reported equal incidence in both the sexes. ${ }^{[4]}$

Additional head is usually unilateral in presentation. ${ }^{[4,9,18,20,25]}$ A unilateral presentation could present as an asymmetric lump in the upper limb and should be considered while arriving at a diagnosis. ${ }^{[26]}$ As most people are right-handed, AHB is mainly believed to be a right-sided condition. ${ }^{[7,15,17,21,25,27,28]}$ Though some studies have identified it to be more common on the left. ${ }^{[4,6,9,11,20]}$ Unilateral cases are common on the right side in males and on the left side in females. ${ }^{[16]}$ In Thai, unilateral cases are common on left side in both sexes. ${ }^{[4]}$ Bilateral cases are usually more common in males. ${ }^{[11,16]}$ In Thai population, it was found to be equal in both sexes. ${ }^{[4]} \mathrm{We}$ observed that unilateral cases were more common, and were mostly observed on the left. Also, the third head was present in majority $(92.3 \%)$ of cases with AHB, which concurs with many earlier studies. ${ }^{[3,4,6,7,9,11,17-19,25,27]}$ More than four heads in BB did not appear in our sample.

The morphology of extra head is variable. It is usually well developed in the males where it is thicker on the left side and longer on the right side. In females, it is considered to be thin, and also longer on the left but thicker on the right. ${ }^{[4,16,21]}$ Average length of an additional head is 11.8 $\mathrm{cm},{ }^{[6,7]}$ which is analogous to our observation. However, Cheema and Singla found it be the $12.9 \mathrm{~cm}$ in sample from north India that was comparable to the findings in Sri Lankan and Colombian populations..$^{[9,17,18]}$

The specific influence of AHB on joint movements is likely to depend on attachments. Muscle fibers from the humerus will act only on the elbow joint and medial origin on the shaft would work in the favor of pronation unlike the long and short heads. ${ }^{[1]}$ The overall muscle power will be enhanced at the insertion site where AHB joins with the main BB tendon. This is likely to reflect in the movements of flexion at the elbow and supination. ${ }^{[8,29]}$

During muscle development in the fetal life, myotome of each somite forms epimere and hypomere. At the location of limb buds, myogenic cells from hypomeres move into the limbs in the fifth week of the intrauterine life. The ventral mass derived from these myoblasts forms muscles of the anterior compartment of the arm including $\mathrm{BB} .{ }^{[30]}$ The definitive structure of muscles depends on various factors like the segmentation of muscle mass, effect of T-box factors, and apoptosis during morphogenesis. ${ }^{[31]} \mathrm{A}$ disturbance in these factors could lead to the formation of accessory muscles. As spinal nerves grow into the limb buds, muscle cell surface molecules direct the growth and distribution of axons. ${ }^{[31]}$ This provides a likely explanation for variation in the nerve course and branching seen with the accessory muscle heads.
Additional head is related superficially to $\mathrm{MCN} .{ }^{[7,17]} \mathrm{MCN}$ passing beneath a large accessory muscle is vulnerable to compression. ${ }^{[18]}$ Though extra head is innocuous in the majority, it becomes clinically relevant in instances of accessory head arching over the neurovascular structures in the arm where compressive symptoms can appear. ${ }^{[8,14,32]} \mathrm{We}$ observed one case of accessory muscle covering median nerve and brachial artery, similar to a case reported by Nakatani et al. ${ }^{[33]}$ In cases where $\mathrm{MCN}$ is absent, the accessory head is supplied by $\mathrm{MN} .^{[3,12,27]}$ Communication between $\mathrm{MN}$ and MCN are clinically significant in the cases of nerve entrapment and also place the nerve at risk during surgical procedures in the arm. The connecting branches should be carefully pursued and approached to avoid complications related to loss of nerve fibers. ${ }^{[13,33]}$ It has also been proposed that presence of $\mathrm{MCN}$ variation influences the development of extra head. ${ }^{[3]}$ We observed communicating branches with an additional head of BB in $35.7 \%$ cadavers, all unilateral and on the same side as the extra muscle. In comparison to classification by Choi et al., ${ }^{[34]}$ three cases [Figure 2A, 2B, 2C] were similar to pattern $2 \mathrm{a}$ and one case [Figure $2 \mathrm{E}$ ] was similar to pattern 3, and we observed most COBs on left. Cases shown in Figs $2 \mathrm{~B}$ and $2 \mathrm{C}$ in our study were type II, and case $2 \mathrm{E}$ had both types I and II variations as per the description from Venieratos and Anagnostopoulou, whereas, according to the classification proposed by Guerri-Guttenberg and Ingolotti, cases in figures $2 \mathrm{~B}$ and $2 \mathrm{C}$ are similar to type I-A-1-D, and case $2 \mathrm{E}$ is comparable to type I-A-2-PD. Case 2A, however, did not fit these two classifications. Also, the simultaneous presence of an additional head of BB was not noticed in any these studies. ${ }^{[12,13]}$

\section{Conclusion}

Based on the present study, incidence of additional head in biceps brachii is $18.3 \%$ in the Indian population. AHB is more common in males and is most likely to be seen as a third head on the left side. AHB can be associated with ipsilateral nerve communications, which would possibly complicate surgical procedures in arm. Awareness of these variations is also important for the interpretation of radiological scans.

\section{References}

1. Standring S. Gray's anatomy-the anatomical basis of clinical practice. 41st edn. London: Elsevier; 2016.

2. Testut L. Les anomalies musculaires chez l'homme. Paris: Masson. 1884. p. 370-397.

3. Bergman RA, Thompson SA, Afifi AK, Saadeh FA. Compendium of human anatomic variations. Baltimore: Urban \& Schwarzenberg; 1988

4. Techataweewan N, Toomsan Y, Maneenin C, Tungsrithong N, Tayles N. Supernumerary heads to biceps brachii muscle and Asian population history. Homo 2016; 67: 484-491.

5. Gheno R, Zoner CS, Buck FM, Nico MAC, Haghighi P, Trudell DJ, Resnick D. Accessory head of biceps brachii muscle: Anatomy, histology and, MRI in cadavers. AJR Am J Roentgenol 2010; 194: 80-83.

6. Nasr AY, Hussein AM. Morphology and clinical implication of the extra-head of biceps brachii muscle. Folia Morphol 2013; 72: 349356. 


\section{Verma d Sakthivel; Revisited Anatomy of Additional Hteads of Biceps Brachit}

7. Ballesteros LE, Forero PL, Buitrago ER. Evaluation of additional head of biceps brachii: a study with autopsy material. Folia Morphol 2014; 73: 193-198.

8. Kumar H, Das S, Rath G. An anatomical insight into the third head of biceps brachii muscle. Bratisl Lek Listy 2008; 109: 76-78.

9. Cheema P, Singla R. Low incidence of the third head of the biceps brachii in the North Indian population. J Clin Diagn Res 2011; 5: 1323-1326.

10. Nayak SR, Prabhu LV, Sivanandan R. Third head of biceps brachii: a rare occurrence in the Indian population. Ann Anat 2006; 188: $159-161$.

11. Asvat R, Candler P, Sarmiento EE. High incidence of third head of biceps brachii in South African populations. J Anat 1993; 182: 101-104.

12. Guerri-Guttenberg RA, Ingolotti M. Classifying musculocutaneous nerve variations. Clin Anat 2009; 22: 671-683.

13. Venieratos D, Anagnostopoulou S. Classification of communications between the musculocutaneous and median nerves. Clin anat 1998; 11: 327-331.

14. Audenaert EA, Barbaix EJ, Hoonacker PV, Berghs BM. Extraarticular variants of the long head of the biceps brachii: A reminder of embryology. J Shoulder Elbow Surg 2008; 17: 114117.

15. Abu-Hijleh MF. Three-headed biceps brachii muscle associated with duplicated musculocutaneous nerve. Clin Anat 2005; 18: 376379.

16. Kosugi K, Shibata S, Yamashita H. Supernumerary humeral heads of the biceps brachii and branching pattern of the musclocutaneous nerve in Japanese. Surg Radiol Anat 1992; 14: 175-185.

17. Rincon F, Rodriguez ZI, Sanchez A, Leon A, Gonzalez LF. The anatomic characteristics of the third head of biceps brachii muscle in Colombian population. Rev Chil Anat 2002; 20: 197-200.

18. Ilayperuma I, Nanayakkara G, Palahepitiya N. Incidence of humeral head of biceps brachii muscle: anatomical insight. Int $\mathrm{J}$ Morphol 2011; 29: 221-225.

19. Neto HS, Camilli JA, Andrade JCT, Filho JM, Marques MJ. On the incidence of the biceps brachii third head in Brazilian whites and blacks. Ann Anat 1998; 180: 69-71.

20. Silva DA, Goke K, Savedra CMS, Pires LAS, Leite TFO, Chagas CAA. Variations of the biceps brachii muscle in Brazilians. Int $\mathrm{J}$ Anat Res 2016; 4: 2444-2449.

21. Rai R, Ranade AV, Prabhu LV, Pai MM, Prakash. The third head of the biceps brachii in the Indian population. Singapore Med J 2007; 48: 929-931.

22. Schwerdtfeger LA, Pascoe MA, Clapp T. High incidence of a third head of biceps brachii in females. Translational Research in Anatomy 2018; 12: 25-27.

23. Pakhale SV, Borole BS, Mahajan AA. A study on the accessory head of the biceps brachii in Indians which was done during cadaver dissections. J Clin Diagn Res 2012; 6: 1137-1139.

24. Fraser PR, Howard LW, Rosales AA, Guttmann GD. Bilateral symmetrical supernumerary heads of biceps brachii with rare pectoralis major insertion. Surg Radiol Anat 2015; 37: 299-302.

25. Rodriguez-Niedenfuhr M, Vazquez T, Choi D, Parkin I, Sanudo JR. Supernumerary humeral heads of the biceps brachii muscle revisited. Clin Anat 2003; 16: 197-203.

26. Kervancioglu P, Orhan M. An anatomical study on the threeheaded biceps brachii in human fetuses and clinical relevance. Folia Morphol 2011; 70: 116-120.

27. Al-Kushi AG. Anatomical study of the third head of biceps brachii muscle and its innervation by median nerve in human dissection. $\mathrm{J}$ Clin Med Res 2013; 5: 47-52.

28. Poudel PP, Bhattarai C. Study on the supernumerary heads of biceps brachii muscle in Nepalese. Nepal Med Coll J 2009; 11: 9698.

29. Lee SE, Jung C, Ahn KY, Nam KI. Bilateral asymmetric supernumerary heads of biceps brachii. Anat Cell Bio 2011; 44: $238-240$.

30. Schoenwolf GC, Bleyl SB, BraueR PR, Francis-West PH. Larsen's human embryology. 4th ed. Philadelphia: Churchill Livingstone; 2009.

31. Carlson BM. Human embryology and developmental biology. 5th ed. Philadelphia: Elsevier; 2013.

32. Paraskevas G, Natsis K, Ioannidis O, Papaziogas B, Kitsoulis P, Spanidou S. Accessory muscles in the lower part of the anterior compartment of the arm that may entrap neurovascular elements. Clin Anat 2008; 21: 246-251.

33. Nakatani T, Tanaka S, Mizukami S. Bilateral four-headed biceps brachii muscles: the median nerve and brachial artery passing through a tunnel formed by a muscle slip from the accessory head. Clin Anat 1998; 11: 209-212.

34. Choi D, Rodriguez-Niedenfuhr M, Vazquez T, Parkin I, Sanudo JR. Patterns of connections between the musculocutaneous and median nerves in the axilla and arm. Clin Anat 2002; 15: 11-17.

Copyright: ( $)$ the author(s), publisher. Academia Anatomica International is an Official Publication of "Society for Health Care \& Research Development". It is an open-access article distributed under the terms of the Creative Commons Attribution Non-Commercial License, which permits unrestricted non-commercial use, distribution, and reproduction in any medium, provided the original work is properly cited.

How to cite this article: Verma S, Sakthivel S. Revisited Anatomy of Additional Heads of Biceps Brachii Muscle and Coexisting Musculocutaneous Nerve Variants. Acad. Anat. Int. 2019;5(2):73-77.

DOI: dx.doi.org/10.21276/aanat.2019.5.2.20

Source of Support: Nil, Conflict of Interest: None declared. 